\title{
Palladium-Catalyzed Synthesis of Cyclopentane-Fused Benzocyclobutenes via Tandem Directed Carbopalladation/C-H Bond Functionalization
}

\author{
Myra Beaudoin Bertrand and John P. Wolfe \\ Department of Chemistry, University of Michigan, 930 N. University Ave., Ann Arbor, Michigan, \\ 48109-1055
}

\begin{abstract}
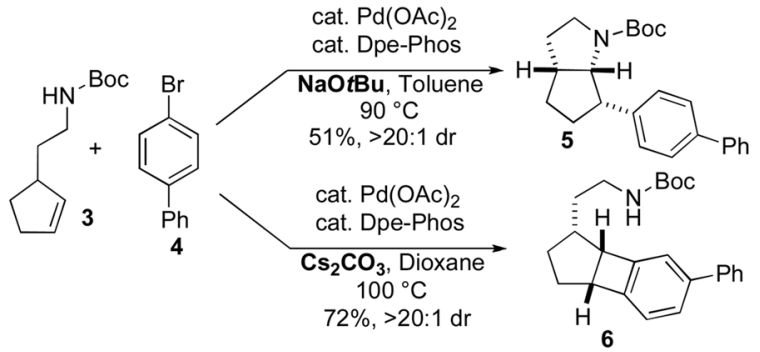

A new Pd-catalyzed reaction for the stereoselective synthesis of cyclopentane-fused benzocyclobutenes is described. These transformations likely proceed via carbamate-directed carbopalladation followed by intramolecular $\mathrm{C}-\mathrm{H}$ activation of an alkylpalladium intermediate. The mechanistic relationship between these transformations and Pd-catalyzed reactions of $\gamma$ - $n$-Bocamino)alkenes with aryl bromides that afford pyrrolidines is discussed. Differences in reactivity between Pd-amino and Pd-amido complexes appear to play a key role in the outcome of these transformations.
\end{abstract}

\footnotetext{
During the course of studies on Pd-catalyzed carboamination reactions of N-protected $\gamma$ aminoalkenes ${ }^{1}$ we observed that the use of the weak base $\mathrm{Cs}_{2} \mathrm{CO}_{3}$ in transformations of terminal alkene substrates (e.g., 1) provided 2-benzylpyrrolidine derivatives (e.g., 2) in yields that were comparable to those obtained with the stronger base $\mathrm{NaO} t \mathrm{Bu}\left(\right.$ eq 1). ${ }^{2}$ However, when the $\mathrm{Cs}_{2} \mathrm{CO}_{3}$ conditions were employed with cyclopentene-derived substrate 3 , a surprising result was obtained. As shown below, the Pd-catalyzed reaction of $\mathbf{3}$ with 4-bromobiphenyl (4) in the presence of $\mathrm{Cs}_{2} \mathrm{CO}_{3}$ did not provide the expected product 5 , but instead generated benzocyclobutene derivative $\mathbf{6}$ in $72 \%$ yield and $>20: 1 \mathrm{dr}$ (eq 3). This result is in marked contrast with the reaction of $\mathbf{3}$ with $\mathbf{4}$ in the presence of $\mathrm{NaO} t \mathrm{Bu},{ }_{1}$ which affords the expected heterocycle 5 in $51 \%$ yield (eq 2). ${ }^{3}$
} 


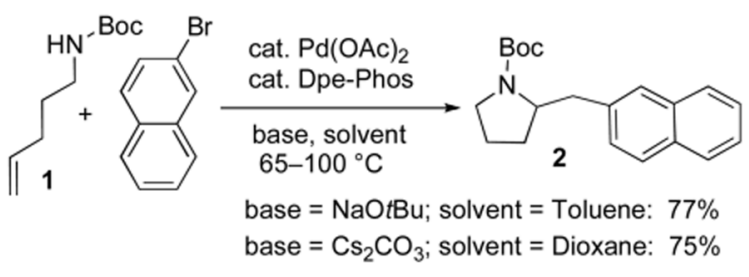

(1).

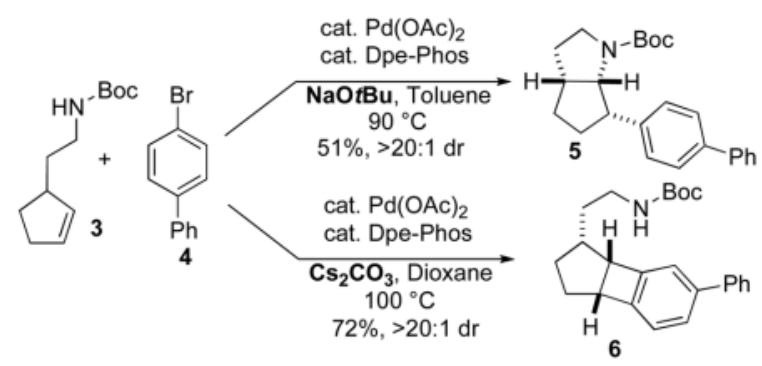

(2), (3).

The generation of benzocyclobutene $\mathbf{6}$ is both synthetically and mechanistically interesting. 4 Benzocyclobutenes are widely employed as precursors to ortho-quinodimethides, which are known to undergo facile [4+2] cycloaddition reactions, ${ }^{5}$ and can also be employed in polymerizations. ${ }^{6}$ Moreover, the surprising effect of base on the reactivity of $\mathbf{3}$ raises questions about the mechanistic relationship between the reactions shown in eqs 1-3. In this Letter we describe our preliminary studies on the preparation of benzocyclobutenes via coupling of $\mathbf{3}$ with aryl bromides, and present a mechanistic hypothesis that accounts for the observed effect of base on these transformations.

To explore the scope of the Pd-catalyzed benzocyclobutene forming process, we examined reactions of $\mathbf{3}$ with various $p-, m$ - and $o$-substituted aryl bromides. As shown in Table 1, reactions of $p$-substituted starting materials afforded products substituted exclusively at the 2position of the aromatic ring (entries 1-4). Similarly high regioselectivity was obtained in reactions of $o$-substituted aryl bromides, which afforded products bearing substituents at the 5 -position (entries 5-6). The regioselectivities observed in reactions of $m$-substituted aryl bromides were dependent on the nature of the substituent. Although the reaction of $\mathbf{3}$ with $\mathrm{m}$ bromotoluene proceeded with good regioselectivity (entry 7), the coupling of $\mathbf{3}$ with $\mathrm{m}$ bromoanisole afforded a 2:1 mixture of regioisomers (entry 8).

The major side products formed in reactions between $\mathbf{3}$ and either electron-rich or -neutral aryl bromides were arylated cyclopentanes (7), although in many reactions trace amounts of bicyclic products $\mathbf{8}-\mathbf{1 0}$ were detected by ${ }^{1} \mathrm{H}$ NMR analysis of the crude reaction mixtures (Fig. 1). ${ }^{7}$

Although the benzocyclobutene-forming reactions proceeded smoothly with many aryl bromides, the Pd-catalyzed coupling of $\mathbf{3}$ with the electron-poor substrate 3bromobenzotrifluoride afforded a 26:39:23 mixture of 11:8:9 (eq 4 ); 8 upon purification 11 was obtained in $24 \%$ yield. In addition, the Pd-catalyzed reaction of $\mathbf{3}$ with 1-bromo-2methylnaphthalene proceeded slowly and in low conversion (ca. 40\%) to afford 5-aryl azabicyclo[3.3.0] octane $\mathbf{1 2}$ in $26 \%$ isolated yield (eq 5). ${ }^{9}$ 


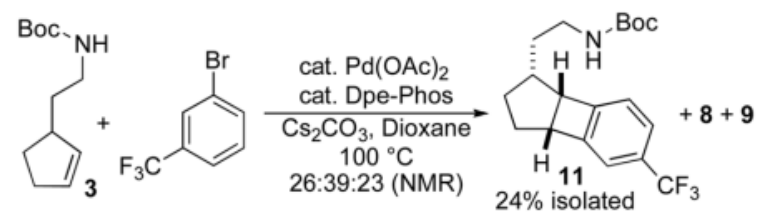

(4).

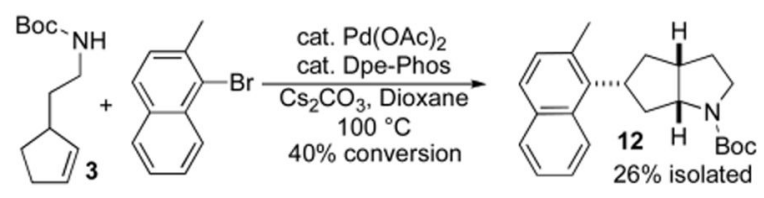

(5).

The dependence of base on the outcome of Pd-catalyzed reactions of $\mathbf{3}$ with aryl bromides (eqs 2-3) likely results from differences in reactivity of palladium amino complexes vs. palladium amido complexes. ${ }^{10}$ As shown in Scheme 1, oxidative addition of the aryl bromide to $\operatorname{Pd}(0)$ generates 13, which can bind the carbamate to provide 14. In the presence of a base, amino complex 14 can potentially be converted to amido complex 18. However, with the weak base $\mathrm{Cs}_{2} \mathrm{CO}_{3}$ this process should be relatively slow due to the low solubility of $\mathrm{Cs}_{2} \mathrm{CO}_{3}, 10$ and the equilibrium between 14 and 18 may favor $\mathbf{1 4}$. In contrast, when the relatively strong, soluble base $\mathrm{NaO} t \mathrm{Bu}$ is employed, the conversion of $\mathbf{1 4}$ to $\mathbf{1 8}$ is relatively fast, and the equilibrium favors amido complex $18 .^{10,11}$

The benzocyclobutene products formed when $\mathrm{Cs}_{2} \mathrm{CO}_{3}$ is used as base are likely generated via directed carbopalladation 12,13 of amino complex 14 to provide the sterically hindered alkylpalladium intermediate $\mathbf{1 5}$, which lacks $\beta$-hydrogen atoms syn to the metal. Intramolecular aryl C-H bond activation 4,14 of $\mathbf{1 5}$ provides 16 and an equivalent of $\mathrm{HBr}$, which is neutralized by $\mathrm{Cs}_{2} \mathrm{CO}_{3}$ Complex 16 is then converted to benzocyclobutene 17 via $\mathrm{C}-\mathrm{C}$ bond-forming reductive elimination. ${ }^{4,15}$ The arylated cyclopentane side product 7 may result from competing protonation of the $\mathrm{Pd}-\mathrm{C}$ bond(s) of $\mathbf{1 5}$ or $\mathbf{1 6}$. The conversion of the electron-poor $m$-bromobenzotrifluoride to a mixture of $\mathbf{1 1}, \mathbf{8}$, and $\mathbf{9}$ is likely due to enhancement of the $\mathrm{N}-$ $\mathrm{H}$ proton acidity of $\mathbf{1 4}$ when the complex bears an electron-withdrawing aryl substituent, which would shift the 14/18 equilibrium toward 18 .

Under conditions that facilitate rapid and/or thermodynamically favorable formation of amido complex 18, the reactions likely proceed via syn-amidopalladation as described previously to generate $19,{ }^{1}$ which is converted to 8 via $\mathrm{C}-\mathrm{C}$ bond-forming reductive elimination. Alternatively, 19 can also be transformed to 9 or 10 via $\beta$-hydride elimination/ reinsertion processes. ${ }^{1 \mathrm{a}, \mathrm{c}}$

The differences in reactivity observed between substrates bearing terminal alkenes (e.g., 1) and cycloalkene substrate $\mathbf{3}$ may be due either to the influence of alkene size on the position of the 18/19 equilibrium, the influence of substrate sterics on the rate of $\mathrm{C}-\mathrm{C}$ bond-forming reductive elimination from $\mathbf{1 9}$, or the influence of alkene substitution on the relative rates of alkene insertion into the $\mathrm{Pd}-\mathrm{C}$ bond of $\mathbf{1 4}$ vs. the $\mathrm{Pd}-\mathrm{N}$ bond of $\mathbf{1 8}$. In addition, the fact that Pdcatalyzed reactions of $\mathbf{3}$ with aryl halides lacking $o$-hydrogen atoms are converted to azabicyclooctanes (e.g., 12) in the presence of $\mathrm{Cs}_{2} \mathrm{CO}_{3}$ suggests that the carbopalladation of 14 is either reversible, ${ }^{16}$ or very slow with bulky aryl groups. Our current data do not allow us to differentiate between these possibilities.

In conclusion, we have developed a new transformation for the conversion of 3 to cyclopentanefused benzocyclobutenes via an unprecedented sequence of heteroatom directed carbopalladation followed by intramolecular aryl $\mathrm{C}-\mathrm{H}$ bond activation. These are the first 
examples of reactions that exploit directed carbopalladation for the generation and functionalization of alkylpalladium intermediates that lack syn- $\beta$-hydrogen atoms. Importantly, the results described above illustrate that differences in reactivity between Pdamino and Pd-amido complexes can be exploited to allow the construction of strikingly different products from common starting materials. Further studies on the scope of this method and applications of these concepts are currently underway.

\section{Supplementary Material}

Refer to Web version on PubMed Central for supplementary material.

\section{Acknowledgements}

The authors thank the NIH-NIGMS (GM-071650) for financial support of this work. Additional support was provided by the Camille and Henry Dreyfus Foundation, Research Corporation, Eli Lilly, Amgen, and 3M.

\section{References}

1. (a) Ney JE, Wolfe JP. Angew Chem, Int Ed 2004;43:3605. (b) Bertrand MB, Wolfe JP. Tetrahedron 2005;61:6447. (c) Ney JE, Wolfe JP. J Am Chem Soc 2005;127:8644. [PubMed: 15954769] (d) Bertrand MB, Wolfe JP. Org Lett 2006;8:2353. [PubMed: 16706524] (e) Wolfe JP. Eur J Org Chem 2007:571.and references cited therein

2. Bertrand MB, Leathen ML, Wolfe JP. Org Lett 2007;9:457. [PubMed: 17249786]

3. Dpe-Phos = bis(2-diphenylphosphinophenyl)ether.

4. For Pd-catalyzed reactions of aryl bromides with norbornene and related bicyclo[2.2.n]alkenes that afford benzocyclobutene products, see: (a) Catellani M, Chiusoli GP, Ricotti S. J Organomet Chem 1985;296:C11. (b) Catellani M, Chiusoli GP, Ricotti S, Sabini F. Gazz Chim Ital 1985;115:685. (c) Catellani M, Ferioli L. Synthesis 1996:769.

5. (a) Sadana AK, Saini RK, Billups WE. Chem Rev 2003;103:1539. [PubMed: 12683790] (b) Mehta G, Kotha S. Tetrahedron 2001;57:625.

6. Farona MF. Prog Polym Sci 1996;21:505.

7. These structures were assigned by comparison of NMR spectra to those obtained for isolated samples of 5,12 , and a previously described $N$-aryl analog of 10 . See reference $1 \mathrm{c}$.

8 . The remainder of the mixture consisted of $5 \% \mathrm{~N}$-arylated substrate and $8 \%$ of unidentified products.

9. A similar result was obtained with 2-bromo- $m$-xylene, which afforded a 5-aryl azabicyclo[3.3.0]octane in $30 \%$ yield (ca. $40 \%$ conversion). See the Supporting Information for complete details.

10. Amino complex refers to coordination of the neutral carbamate, whereas amido complex refers to coordination of the deprotonated, anionic carbamate. For discussion of kinetic and thermodynamic effects in amido complex formation, see: a) Meyers C, Maes BUW, Loones KTJ, Bal G, Lemiere GLF, Dommisse RA. J Org Chem 2004;69:6010. [PubMed: 15373485] b) Driver MS, Hartwig JF. Organometallics 1997; 16:5706.

11. When $\mathrm{NaOtBu}$ is employed as base the amido complex could also be generated via reaction of 13 with deprotonated carbamate, or through reaction of the carbamate with a $\mathrm{L}_{\mathrm{n}} \mathrm{Pd}(\mathrm{Ar})(\mathrm{OtBu})$ complex. See: Shekhar S, Hartwig JF. Organometallics 2007;26:340.

12. For early examples, see: a) Kasahara A, Izumi T, Takeda T, Imamura H. B Chem Soc Jpn 1974;47:183. b) Andersson C-M, Larsson J, Hallberg A. J Org Chem 1990;55:5757.

13. For a recent review see: Oestreich M. Eur J Org Chem 2005:783.

14. For recent reviews, see: a) Campeau L-C, Fagnou K. Chem Commun 2006:1253. b) Catellani M. Synlett 2003:298.

15. For tandem intermolecular carbopalladation/C-H functionalization processes involving alkenylpalladium intermediates, see: a) Pinto A, Neuville L, Retailleau P, Zhu J. Org Lett 2006;8:4927. [PubMed: 17020338] b) Furuta T, Asakawa T, Iinuma M, Fujii S, Tanaka K, Kan T. Chem Commun 2006:3648. 
16. a) Campora J, Gutierrez-Puebla E, Lopez JA, Monge A, Palma P, del Rio D, Carmona E. Angew Chem, Int Ed 2001;40:3641. b) Catellani M, Frignani F, Rangoni A. Angew Chem, Int Ed 1997;36:119. 

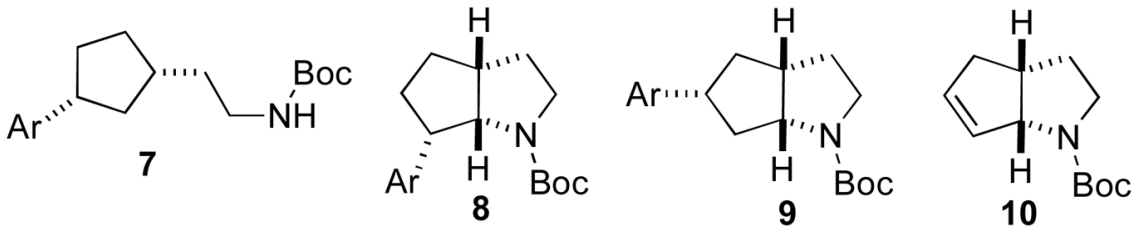

Figure 1.

Side products 


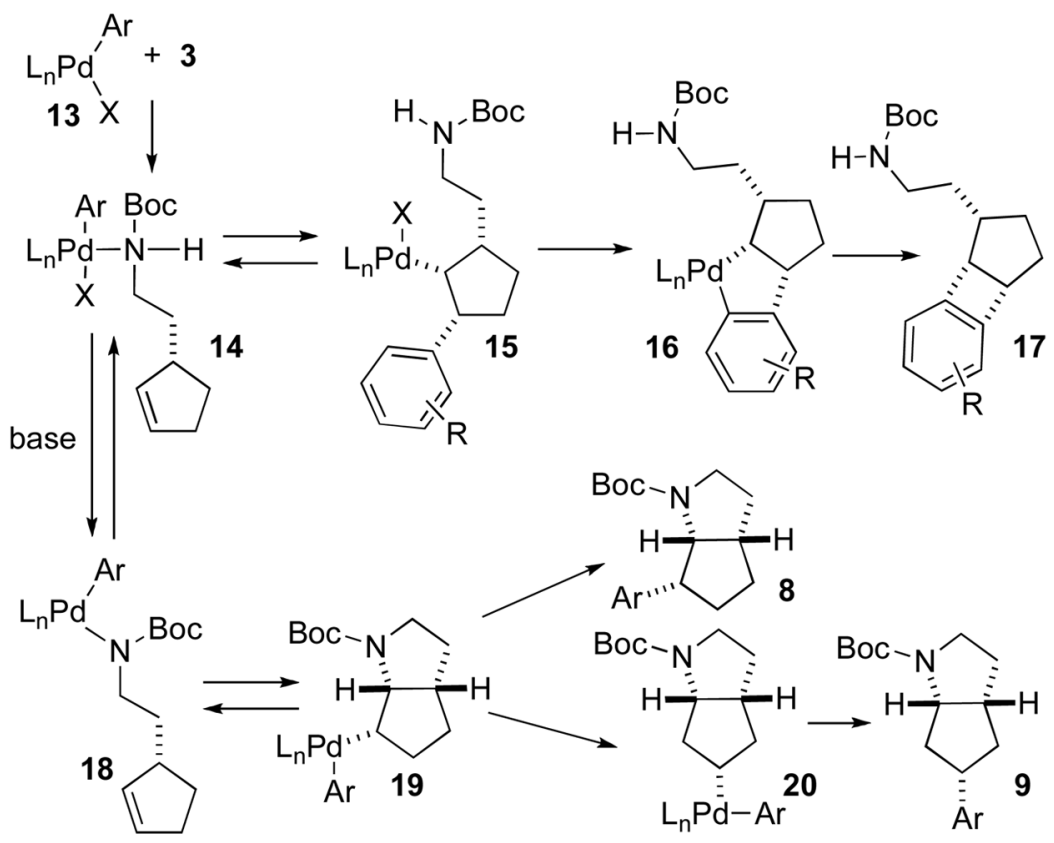

Scheme 1.

Org Lett. Author manuscript; available in PMC 2008 September 3. 
Table 1

Synthesis of Benzocyclobutenes from $3^{a}$

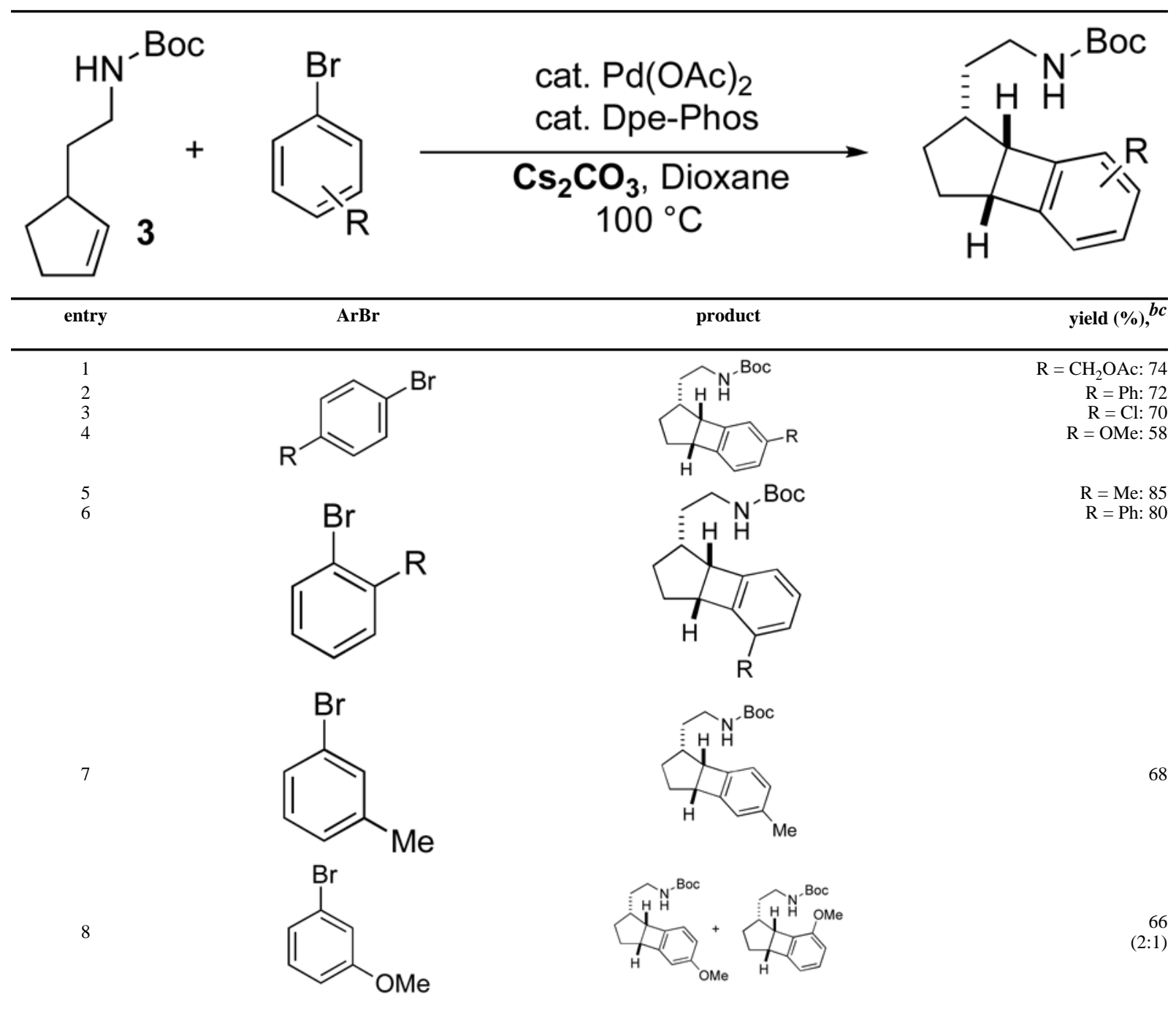

${ }^{a}$ Conditions: 1.0 equiv 3, 1.2. equiv $\mathrm{ArBr}, 2.3$ equiv $\mathrm{Cs}_{2} \mathrm{CO}_{3}, 4 \mathrm{~mol} \% \mathrm{Pd}(\mathrm{OAc})_{2}, 8 \mathrm{~mol} \%$ Dpe-Phos, dioxane $(0.25 \mathrm{M}), 100{ }^{\circ} \mathrm{C}$.

${ }^{b}$ Yields refer to average isolated yields obtained in two or more experiments.

${ }^{c}$ All products were obtained with $>20: 1 \mathrm{dr}$ and $>20: 1$ regioselectivity unless otherwise noted. 